Article

\title{
Involvement of G-Protein-Coupled Receptor 40 in the Inhibitory Effects of Docosahexaenoic Acid on SREBP1-Mediated Lipogenic Enzyme Expression in Primary Hepatocytes
}

\author{
Seungtae On ${ }^{\dagger}$, Hyun Young Kim ${ }^{\dagger}$, Hyo Seon Kim ${ }^{\circledR}$, Jeongwoo Park and Keon Wook Kang ${ }^{*}$ \\ College of Pharmacy and Research Institute of Pharmaceutical Sciences, Seoul National University, \\ Seoul 08826, Korea; seungtae.on@gmail.com (S.O.); hens93@snu.ac.kr (H.Y.K.); hyoseonkim@snu.ac.kr (H.S.K.); \\ jwpark0110@snu.ac.kr (J.P.) \\ * Correspondence: kwkang@snu.ac.kr \\ + These authors contributed equally to this work.
}

Received: 16 April 2019; Accepted: 26 May 2019; Published: 28 May 2019

\begin{abstract}
Nonalcoholic fatty liver disease is a frequent liver malady, which can progress to cirrhosis, the end-stage liver disease if proper treatment is not applied. Omega-3 fatty acids, such as docosahexaenoic acid (DHA) and eicosapentaenoic acid, have been clinically proven to lower serum triglyceride levels. Various physiological activities of omega-3 fatty acids are due to their agonistic actions on G-protein-coupled receptor 40 (GPR40) and GPR120. Lipid droplets (LD) accumulation in hepatocytes confirmed that DHA treatment reduced the number of larger $\left(>10 \mu \mathrm{m}^{2}\right)$ LDs, as well as the total area of LDs. Moreover, DHA lowered protein and mRNA expression levels of lipogenic enzymes such as fatty acid synthase (FAS), acetyl-CoA carboxylase and stearoyl-CoA desaturase-1 (SCD-1) in primary hepatocytes incubated with liver $\mathrm{X}$ receptor (LXR) agonist T0901317 or high glucose and insulin. DHA also decreased protein expression of nuclear and precursor sterol response-element binding protein (SREBP)-1, a key lipogenesis transcription factor. We further found that exposure of murine primary hepatocytes to DHA for $12 \mathrm{~h}$ increased GPR40 and GPR120 mRNA levels. Specific agonists (Compound A for GPR120 and AMG-1638 for GPR40), hepatocytes from GPR120 knock-out mice and GPR40 selective antagonist (GW1100) were used to assess whether DHA's antilipogenic effects are mediated through GPR120 or GPR40. Compound A did not decrease SREBP-1 and FAS protein expression in hepatocytes exposed to T0901317 or high glucose with insulin. Moreover, DHA downregulated lipogenesis enzyme expression in GPR120-null hepatocytes. In contrast, AMG-1638 lowered SREBP-1 and SCD-1 protein levels. Additionally, GW1100, a GPR40 antagonist, reversed the antilipogenic effects of DHA. Collectively, our data demonstrate that DHA downregulates the expression SREBP-1-mediated lipogenic enzymes via GPR40 in primary hepatocytes.
\end{abstract}

Keywords: GPR40; GPR120; DHA; omega-3 fatty acid; SREBP-1; hepatocytes

\section{Introduction}

Nonalcoholic fatty liver disease (NAFLD) affects 80-100 million people in the U.S. alone [1]. Most patients in the U.S., who visit primary care providers for routine checkup have elevated levels of alanine aminotransferase (ALT) and aspartate aminotransferase (AST), which are markers of liver damage [2]. Among those with elevated AST and ALT levels, 33 percent are eventually diagnosed with NAFLD [2]. This pattern is not limited to the Western world. In Asia, 25 percent of individuals aged $>18$ years are diagnosed with NAFLD [3]. Even though this widespread disease has no specific 
signs or symptoms, it can progress to nonalcoholic steatohepatitis (NASH) and eventually lead to cirrhosis [4]. Although treatment options for NAFLD are limited, thiazolidinediones and vitamin $\mathrm{E}$ have been proven to effectively manage symptoms [5].

Omega-3 fatty acid provides an energy source as nutrient, but also act as a remedy for serum hyperlipidemia. Commercially available fish oil supplements are one of the most popular over-the-counter medications for the management of elevated serum triglyceride (TG) levels. In the U.S. alone, about 18.8 million adults are taking fish oil supplements [6]. Omega-3-acid ethyl esters, such as Omacor $^{\circledR}$ and Lovaza ${ }^{\circledR}$, are widely used as prescription medications for dyslipidemia [7]. Omega- 3 fatty acid supplementation decreases liver fat and reduces hepatic steatosis, as well as having beneficial effects on most cardiometabolic risk factors. According to clinical studies, dietary supplementation with omega-3 is efficacious for NAFLD management [8]. However, the mechanism of its TG-lowering effect is not fully understood.

Omega-3 fatty acids, such as docosahexaenoic acid (DHA) and eicosapentaenoic acid (EPA), have been recognized as endogenous ligands for G-protein-coupled receptor 40 (GPR40) and G-protein-coupled receptor 120 (GPR120) [9,10]. In animal models, the administration of selective agonists for GPR40 or GPR120 improves biochemical and pathological indices of hepatic steatosis [11,12]. Nevertheless, the proposed direct effects of omega-3 fatty acids on the G-protein-coupled receptor (GPCR) in hepatocytes are largely uncharacterized and controversial. In the present study, we assessed the effect of DHA on hepatic lipogenesis and attempted to clarify the roles of GPR40 and GPR120 in antilipogenesis effect of DHA in mouse primary hepatocytes.

\section{Results}

2.1. Downregulation of Sterol Regulatory Element Binding Protein (SREBP)-1-Dependent Lipogenic Enzyme Expression by DHA in Primary Hepatocytes

Public microarray data comparing control mice with mice receiving omega-3 fish oil for 2 weeks were analyzed to assess whether omega-3 fatty acids functionally benefit liver (GSE32706). Gene ontology analyses revealed that the genes, including those involved with lipid metabolic processes and cholesterol biosynthetic processes, were mainly altered for similar functional annotations in the liver tissues of fish-oil-fed mice (Figure S1A). In addition, expression of genes involved in lipid metabolism and fatty acid synthesis was repressed in the fish-oil-fed group (Figure S1A). Moreover, fish oil diet led to a significant reduction in the expression of several genes, including srebf1, acacb, fasn, and scd 1 which are required to control hepatic TG synthesis (Figure S1B).

The SREBP1 transcription factor is a critical regulator of fatty acid homeostasis in hepatocytes. Activation of SREBP1 controls the expression of a range of lipogenic enzymes, such as fatty acid synthase (FAS), acetyl-coenzyme A carboxylase (ACC), and stearoyl-CoA desaturase-1 (SCD-1) [13]. Hence, we analyzed the effects of DHA and EPA ( $300 \mu \mathrm{M}$, each) on the expression of SREBP1 and its downstream lipogenesis enzymes. The levels of FAS, ACC, and SCD-1 were diminished in mouse primary hepatocytes treated with DHA or EPA for $12 \mathrm{~h}$, and the degree of inhibition was more prominent in DHA-treated hepatocytes (Figure 1A). The protein level of the precursor form of SREBP-1 (preSREBP-1) was decreased in primary hepatocytes in response to DHA (Figure 1B). To gain further insight into the antilipogenic properties of DHA, primary hepatocytes were treated with liver $\mathrm{X}$ receptor (LXR) agonist T0901317 (T090) to stimulate LXR-dependent SREBP-1 activation. T090-induced protein expression of nuclear SREBP-1 and SCD-1 were decreased significantly following pretreatment of hepatocytes with $300 \mu \mathrm{M}$ DHA for $12 \mathrm{~h}$ (Figure 1C). Although the levels of preSREBP-1, FAS, and ACC were marginally elevated by T090, all the protein expression decreased in response to the DHA treatment (Figure 1D and Figure S2A). Primary hepatocytes were exposed to high glucose with insulin condition to confirm the antilipogenic properties of DHA in metabolic dysfunction. As expected, the amounts of lipogenic proteins involved in TG synthesis, such as preSREBP-1, nSREBP-1, FAS, ACC, and SCD-1, increased under the high glucose with insulin condition, and the enhanced levels were reversed by DHA treatment (Figure 1E and Figure S2B). These data support the notion that DHA 
ameliorates the SREBP-1-mediated lipogenesis enzyme expression caused by an LXR agonist or the high glucose with insulin condition.

A

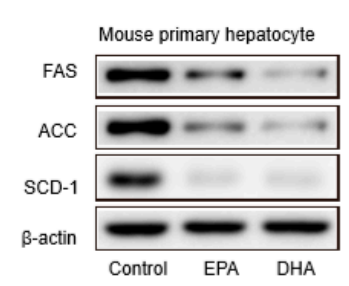

C

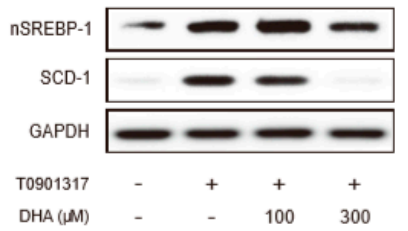

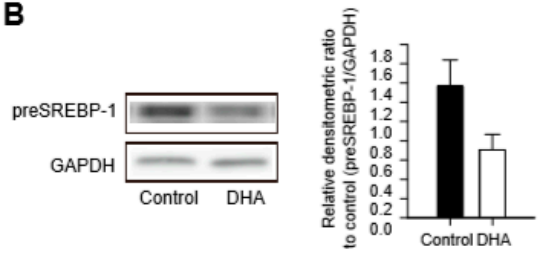

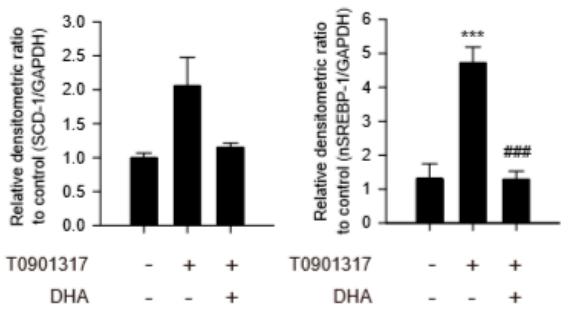

D
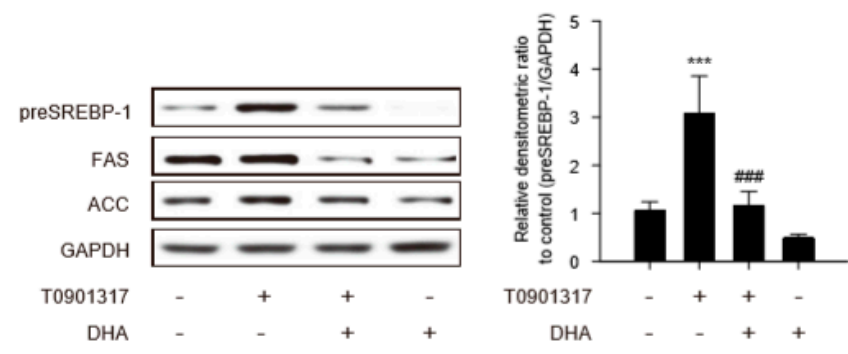

E
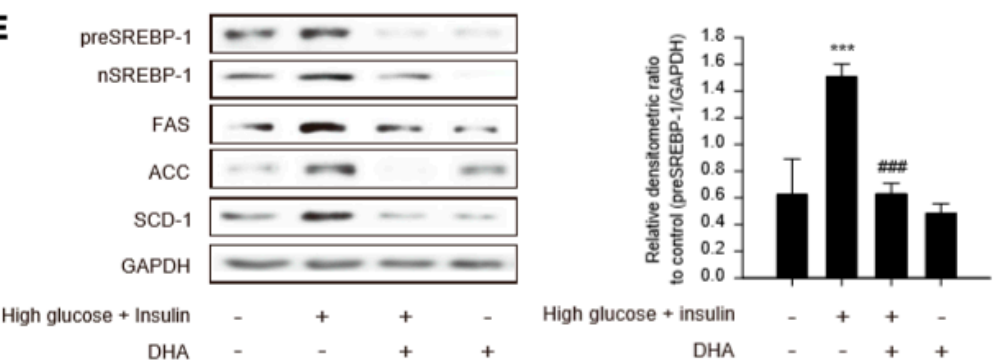

High glucose + insulin

$$
\text { DHA - - + }
$$

Figure 1. Decrease in lipogenesis enzymes after docosahexaenoic acid (DHA) treatment. (A,B) The protein expression level of fatty acid synthase (FAS), acetyl-coenzyme A carboxylase (ACC), stearoyl-CoA desaturase-1 (SCD-1) and precursor form of SREBP-1 (preSREBP-1). Mouse primary hepatocytes were treated with DHA $300 \mu \mathrm{M}$ or eicosapentaenoic acid (EPA) $300 \mu \mathrm{M}$ for $12 \mathrm{~h}$. Data represent means $\pm \mathrm{SD}(n=5)$. GAPDH: Glyceraldehyde 3-phosphate dehydrogenase. (C) In order to screen an optimal DHA concentration that exerts potent antilipogenic effects, primary hepatocytes were treated with DHA $100 \mu \mathrm{M}$ and $300 \mu \mathrm{M}$ for $12 \mathrm{~h}$ followed by T0901317 (T090), liver X receptor (LXR) agonist for additional $12 \mathrm{~h}$. Data represent means $\pm \mathrm{SD}(n=5),{ }^{* * *} p<0.005$ compared with the control group; ${ }^{\# \#} p<0.005$ compared with the T090-treated group (D) Effects of DHA on the expression of lipogenic proteins stimulated by LXR agonist. Primary hepatocytes were treated with DHA $300 \mu \mathrm{M}$ for $12 \mathrm{~h}$ followed by T090 for additional $12 \mathrm{~h}$. Data represent means $\pm \mathrm{SD}(n=5),{ }^{* * *} p<0.005$ compared with the control group; ${ }^{\# \#} p<0.005$ compared with the T090-treated group (E) Effects of DHA on the expression of lipogenic proteins in high glucose with insulin condition. Primary hepatocytes were treated with DHA $300 \mu \mathrm{M}$ for $12 \mathrm{~h}$ followed by $30 \mathrm{mM}$ high-glucose medium for $30 \mathrm{~min}$ and further incubation with $200 \mathrm{nM}$ insulin for $24 \mathrm{~h}$. Data represent means $\pm \mathrm{SD}(n=3), * * * p<0.005$ compared with the control group; ${ }^{\# \#} p<0.005$ compared with the high glucose and insulin group. 


\subsection{DHA-Induced Reduction of Total Area of Lipid Droplets in Hepatocytes}

Hepatic steatosis is defined as abnormal retention of lipid droplets (LD) in hepatocytes, which reflects the dysregulation of TG fat [14]. We explored the effect of DHA on LD formation in hepatocytes. BODIPY ${ }^{\circledR}$ staining showed a greater increase in LDs in hepatocytes incubated under the high glucose and insulin condition, but not with T090 (Figure 2A,B). Interestingly, no difference was detected in the number of LDs per cell between hepatocytes treated with high glucose and insulin and those cotreated with DHA (Figure 2C). Nevertheless, the number of LDs $>10 \mu \mathrm{m}^{2}$, representing pathological lipid accumulation, as well as the total area of LDs per cell decreased in response to DHA (Figure 2D,E). One study showed that the decrease in the size of LDs is due mainly to the lower activity of SCD-1 [15]. The immunoblot results showed a dramatic decrease in SCD-1 with DHA treatment (Figure 1C,D), suggesting that DHA mainly targets enlargement of LDs in hepatocytes.
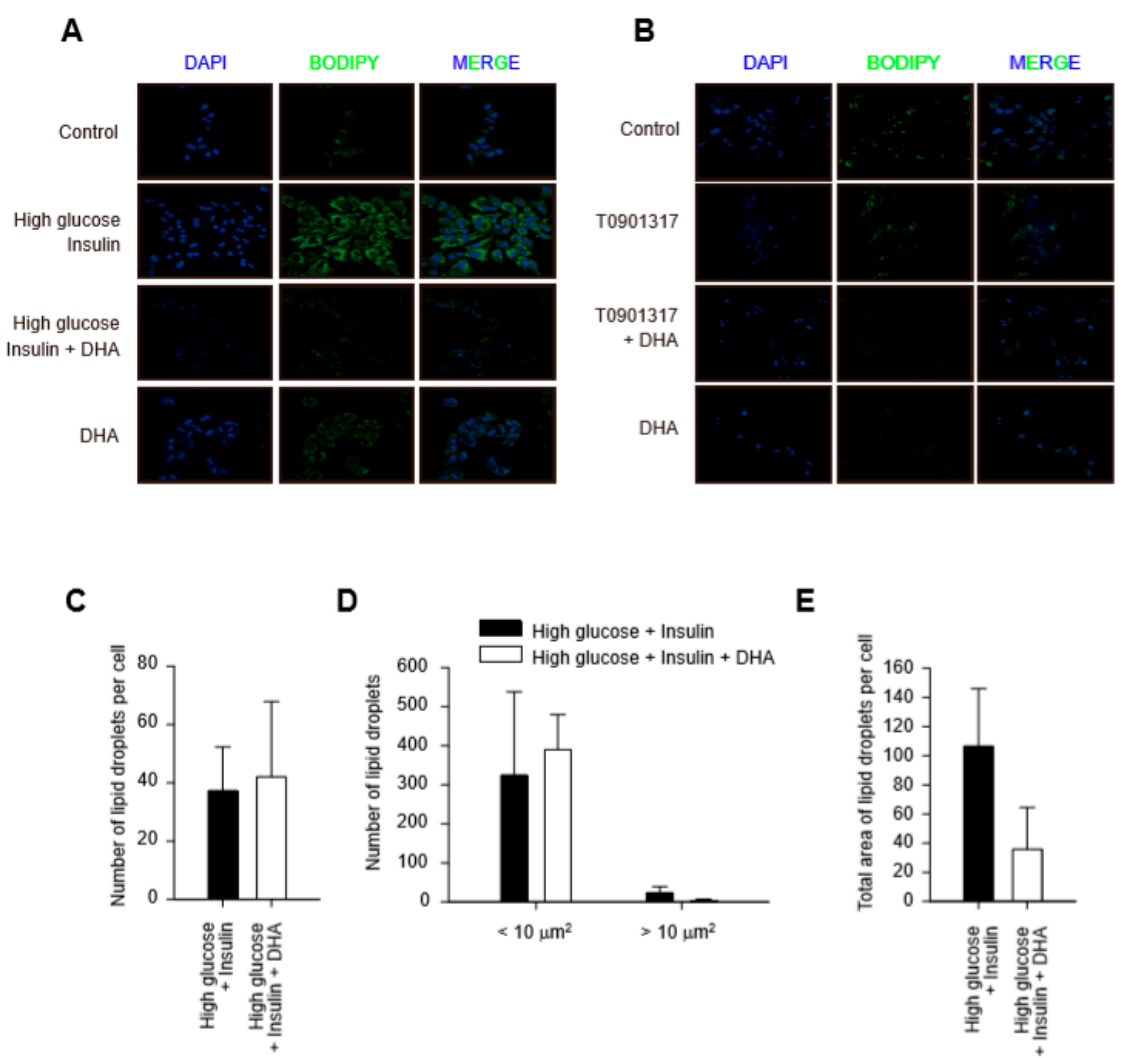

Figure 2. Morphological changes in lipid droplets (LD) after DHA treatment. (A,B) LD formation in hepatocytes by T090 treatment or high glucose with insulin condition. Mouse primary hepatocytes were treated with DHA for $12 \mathrm{~h}$ followed by treatment of T090 for $12 \mathrm{~h}$ or incubation with $30 \mathrm{mM}$ high glucose for $30 \mathrm{~min}$ and further incubation with $200 \mathrm{nM}$ insulin for $24 \mathrm{~h}$. LDs were stained with BODIPY ${ }^{\circledR} 493 / 503$ and visualized by confocal microscopy. (C) Images of 16 random cells from each slide were captured and analyzed by MetaMorph to quantify number of LDs per cell. (D) Numbers of LDs with areas $\leq 10 \mu \mathrm{m}^{2}$ or $>10 \mu \mathrm{m}^{2}$ were analyzed. (E) Total area of LDs per cell were measured and presented as means \pm SEM.

\subsection{Limited Role of GPR 120 in Antilipogenic Effects of DHA in Hepatocytes}

Long-chain fatty acids, such as DHA, act as endogenous ligands on GPR120 and GPR40 and regulates metabolic and inflammatory homeostasis in adipocytes and macrophages $[10,16]$. To investigate whether GPR40 and GPR120 are present in hepatocytes, mRNA levels were determined in HepG2 human hepatoma cell line and mouse primary hepatocytes. mRNA levels of GPR40 and GPR120 were detectable in HepG2 and mouse primary hepatocytes (Figure S3A and Figure 3A). Moreover, exposure to $300 \mu \mathrm{M}$ DHA for $12 \mathrm{~h}$ increased the GPR40 and GPR120 mRNA levels 
(Figure S3A and Figure 3A). Plasma membrane localization of GPR40 and GPR120 in primary hepatocyte was confirmed by immunocytochemistry (Figure 3B). These data demonstrate that GPR40 and GPR120 are expressed in hepatocytes and HepG2 cells are upregulated after DHA exposure. Compound A (CpdA), a specific GPR120 agonist [11], was used to clarify the function of GPR120 on the antilipogenic effects of DHA. Although the basal SCD-1 level was higher in HepG2 cells [17], CpdA concentration-dependently inhibited SCD-1 expression in T090-treated HepG2 cells and primary hepatocytes (Figure 3C and Figure S3B). However, unlike DHA, CpdA up to $10 \mu \mathrm{M}$ did not reduce the expression of preSREBP-1 in primary hepatocytes treated with T090 (Figure 3C). Because series of studies proposed direct interaction between LXR and SCD-1 [18,19], we presumed that downregulation of SCD-1 by CpdA may not be dependent on SREBP-1 pathway. Under the high glucose with insulin condition, CpdA did not reduce the protein level of preSREBP-1, nSREBP-1, and FAS in hepatocytes (Figure 3D and Figure S3C). To confirm these findings, we used age-matched GPR120 knock-out $(\mathrm{KO})$ mice. A pathological examination was performed in hematoxylin and eosin (H\&E) stained liver tissues from 8-weeks-old GPR120 wild-type and $\mathrm{KO}$ mice to rule out preexisting histological conditions (Figure S3D). The decreased lipogenic enzyme expressions by DHA in primary hepatocytes incubated with T090 or high glucose and insulin were not reversed by GPR120 deficiency (Figure 3E,F and Figure S3E,F). These data imply that the inhibitory effects of DHA on the expression of SREBP-1-mediated lipogenic enzymes are minimally associated with GPR120 signaling. 
A

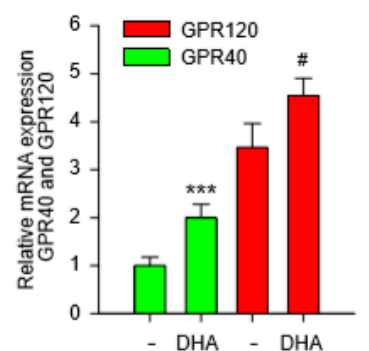

C

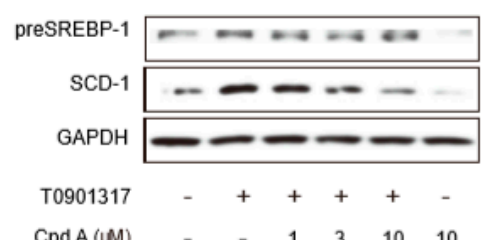

D

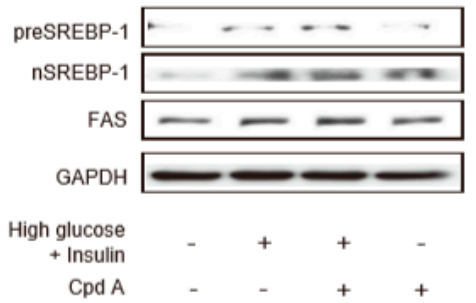

E GPR120 Ko mouse

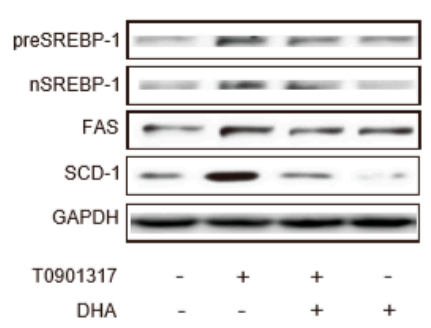

$\mathbf{F}$

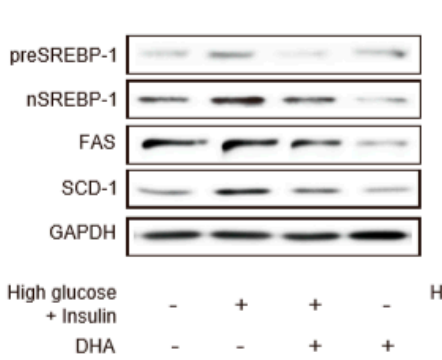

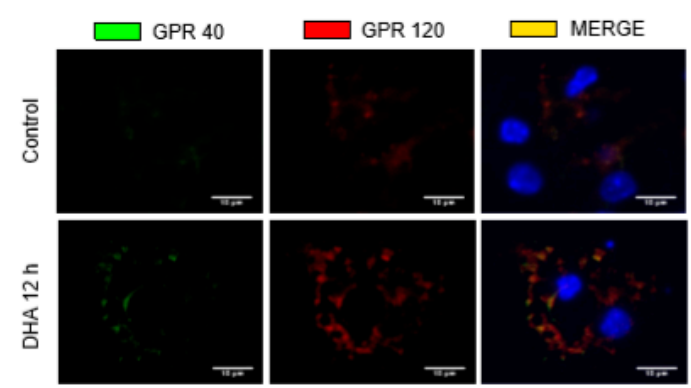
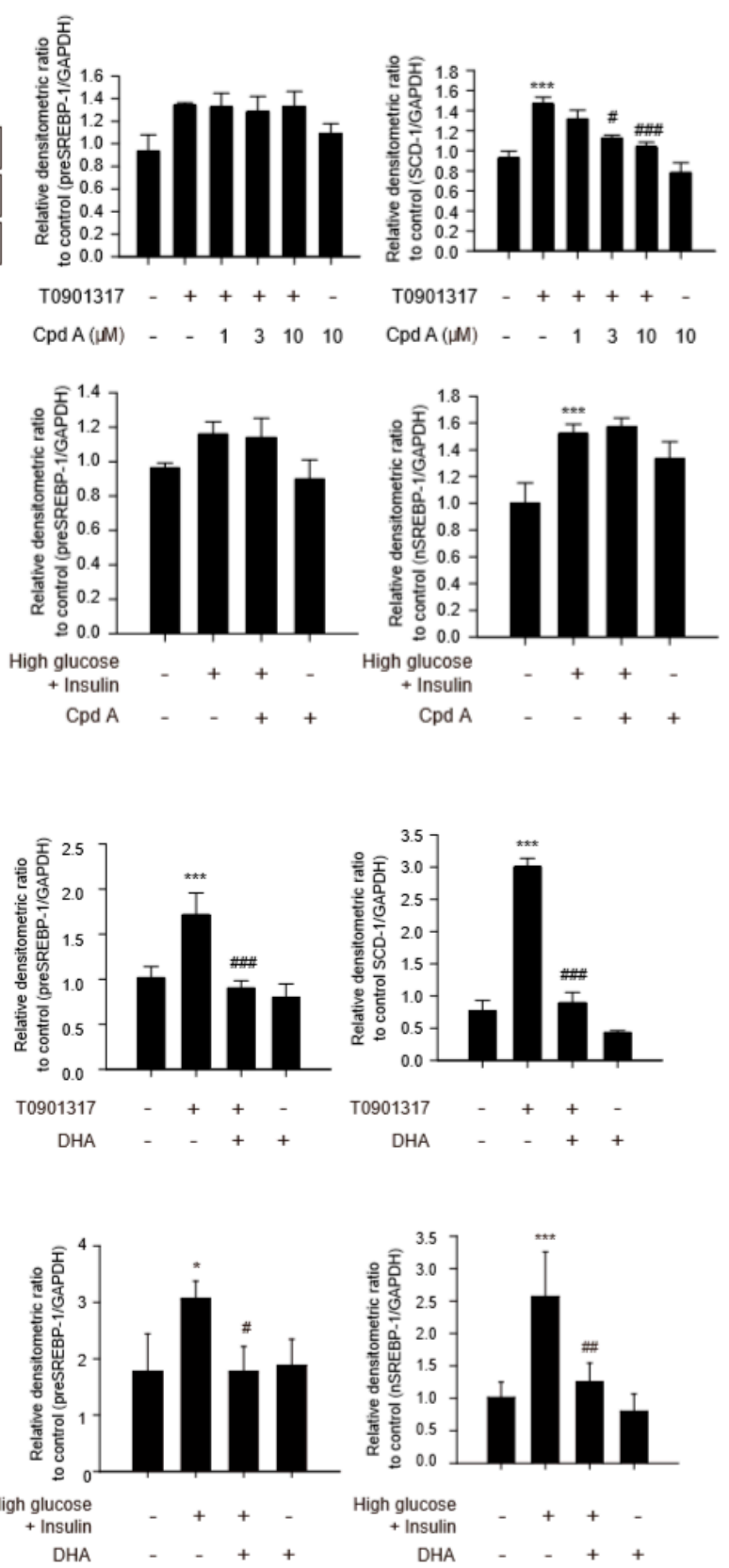

Figure 3. Role of GPR120 in expression of lipogenesis enzymes in hepatocytes. (A) Relative mRNA expressions of GPR40 and GPR120 levels were determined by real-time qPCR analyses in mouse primary hepatocytes. Data represent means $\pm \mathrm{SD}(n=3) .{ }^{* * *} p<0.005$ compared with the GPR40 level of the control group; ${ }^{\#} p<0.05$ compared with the GPR120 level of the control group. 
(B) Immunocytochemistry of GPR40 and GPR120 in primary hepatocytes. Immunofluorescent images of GPR40 and GPR120 at their basal levels and after DHA treatment are shown. (C) Primary hepatocytes were treated with compound A (CpdA) (1-10 $\mu \mathrm{M})$ for $12 \mathrm{~h}$ followed by T090, LXR agonist for additional $12 \mathrm{~h}$. Data represent means $\pm \mathrm{SD}(n=5),{ }^{* * *} p<0.005$ compared with the control group; ${ }^{*} p<0.05$, \#\#\# $p<0.005$ compared with the T090-treated group. (D) Effects of CpdA on the expression of preSREBP1, nSREBP1, and FAS in primary hepatocytes. Primary hepatocytes were treated with CpdA $10 \mu \mathrm{M}$ for 12 $\mathrm{h}$ followed by $30 \mathrm{mM}$ high-glucose medium for $30 \mathrm{~min}$ and further incubation with $200 \mathrm{nM}$ insulin for $24 \mathrm{~h}$. Data represent means $\pm \mathrm{SD}(n=5),{ }^{* * *} p<0.005$ compared with the control group. (E) Effects of DHA on the expression of preSREBP1, nSREBP1, FAS, and SCD-1 in GPR120 knock-out (KO) primary hepatocytes stimulated with T090. GPR120 KO hepatocytes were treated with DHA for $12 \mathrm{~h}$ followed by T090 for additional $12 \mathrm{~h}$. Data represent means $\pm \mathrm{SD}(n=3),{ }^{* * *} p<0.005$ compared with the control group; \# $p<0.05$, \#\#\# $p 0.005$ compared with the T090-treated group. (F) Effects of DHA on the expression of preSREBP-1, nSREBP-1, FAS, and SCD-1 in GPR120 KO primary hepatocytes stimulated with high glucose and insulin. GPR120 KO primary hepatocytes were treated with DHA $300 \mu \mathrm{M}$ for $12 \mathrm{~h}$ followed by $30 \mathrm{mM}$ high-glucose medium for $30 \mathrm{~min}$ and further incubation with $200 \mathrm{nM}$ insulin for $24 \mathrm{~h}$. Data represent means $\pm \mathrm{SD}(n=3),{ }^{*} p<0.05,{ }^{* * *} p<0.005$ compared with the control group; \# $p<0.05,{ }^{\# \#} p<0.01$ compared with the high glucose and insulin group.

\subsection{Involvement of GPR40 in Antilipogenesis Effect of DHA}

We tested the potential role of GPR40 in antilipogenic effects of DHA in hepatocytes. AMG-1638 is a well-characterized GPR40 agonist in murine species and has shown a specific full agonistic activity compared with other candidates [20]. The enhanced expression of preSREBP-1 and SCD-1 caused by T090 was significantly diminished in hepatocytes incubated with $3 \mu \mathrm{M}$ AMG-1638 (Figure 4A). Moreover, $3 \mu \mathrm{M}$ AMG-1638 reduced the protein expression of FAS and SCD-1 as well as preSREBP-1 and nSREBP-1, under the high glucose and insulin condition (Figure 4B). We further assessed the effect of the GPR40 antagonist GW1100 to confirm whether the antilipogenic properties of DHA were related with GPR40 activation. When hepatocytes were co-incubated with both GW1100 and DHA, the inhibitory effects of DHA on the expression of preSREBP-1 and SCD-1 were almost completely reversed by GW1100 in T090-exposed hepatocytes (Figure 4C). Similar results were obtained for GPR120 KO hepatocytes (Figure 4D). Hence, downregulation of SREBP-1-mediated expression of lipogenic enzymes by DHA was under the control of GPR40 in hepatocytes. 

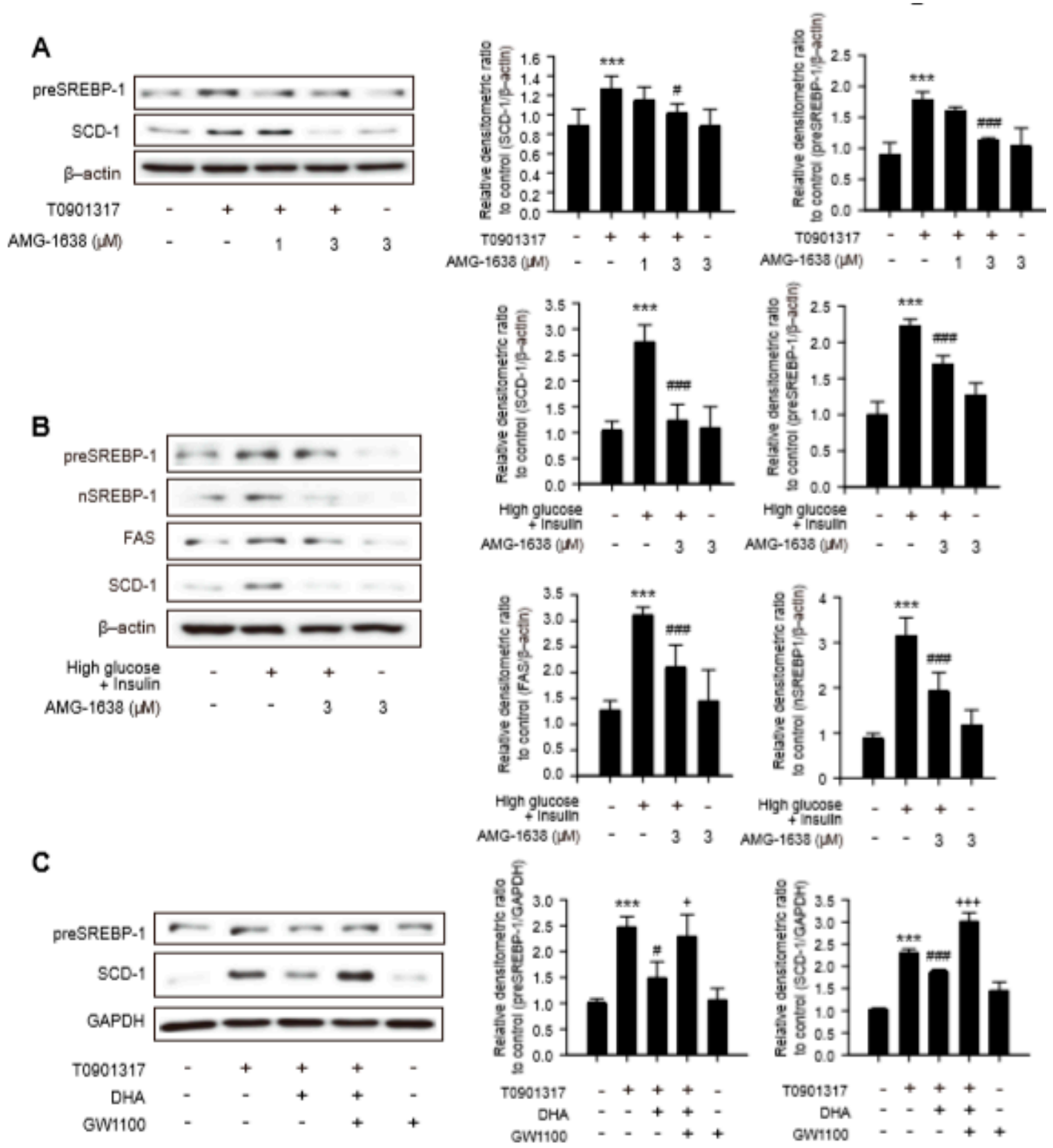

D GPR120 KO Mouse
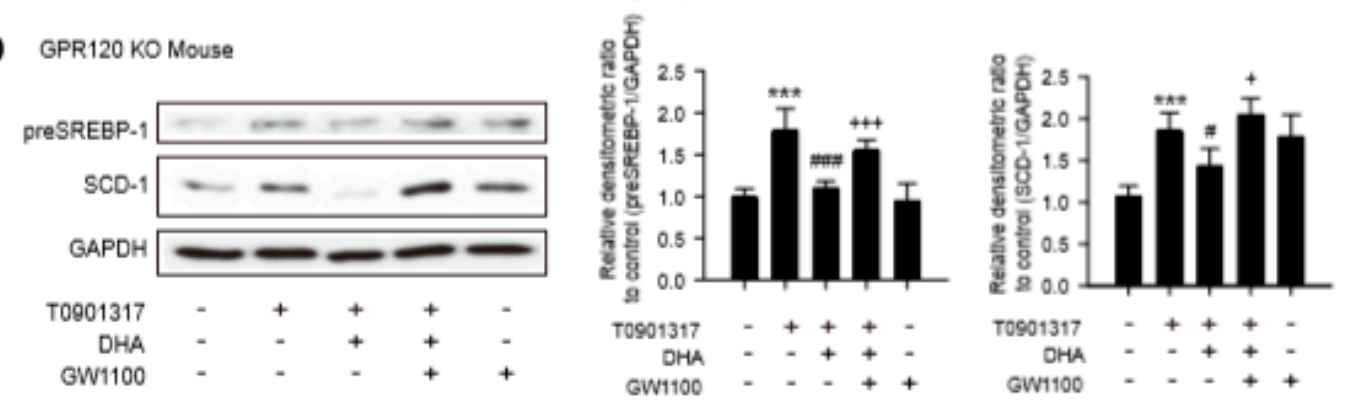

Figure 4. Role of GPR40 in expression of lipogenesis enzymes in hepatocytes. (A) Primary hepatocytes were treated with AMG-1638 ( 1 and $3 \mu \mathrm{M})$ for $12 \mathrm{~h}$ followed by T090 for additional $12 \mathrm{~h}$, and total cell lysates were subjected to immunoblotting for preSREBP-1 and SCD-1. 
Data represent means $\pm \mathrm{SD}(\mathrm{n}=4),{ }^{* * *} \mathrm{P}<0.005$ compared with the control group; ${ }^{\#} p<0.05,{ }^{\# \# \#} p<0.005$ compared with the T090-treated group. (B) Inhibitory effects of AMG-1638 on the protein expression of lipogenic enzymes in high glucose and insulin condition. Primary hepatocytes were treated with $3 \mu \mathrm{M}$ AMG-1638 for $12 \mathrm{~h}$ followed by $30 \mathrm{mM}$ high-glucose medium for $30 \mathrm{~min}$ and further incubation with $200 \mathrm{nM}$ insulin for $24 \mathrm{~h}$. Data represent means \pm SD $(n=4){ }^{* * *} p<0.005$ compared with the control group, ${ }^{\# \# \# ~} p<0.005$ compared with the T090-treated group. (C) Primary hepatocytes were treated with DHA and $10 \mu \mathrm{M}$ GW1100, GPR40 antagonist for $12 \mathrm{~h}$ followed by $30 \mathrm{mM}$ high-glucose medium for $30 \mathrm{~min}$ and further incubation with $200 \mathrm{nM}$ insulin for $24 \mathrm{~h}$. Data represent means $\pm \mathrm{SD}(n=4)$, *** $p<0.005$ compared with the control group; \# $p<0.05$, \#\#\# $p<0.005$ compared with the T090-treated group; ${ }^{+} p<0.05,{ }^{+++} p<0.005$ compared with the T090 and DHA treated group. (D) In GPR120 KO hepatocytes, $10 \mu \mathrm{M}$ GW1100 reversed the antilipogenic effects of DHA. Data represent means \pm SD $(n=4) .{ }^{* * *} p<0.005$ compared with the control group; ${ }^{*} p<0.05$, \#\#\# $p<0.005$ compared with the T090-treated group; $+p<0.05,{ }^{+++} p<0.005$ compared with the T090 and DHA treated group.

\section{Discussion}

DHA and EPA are omega-3 fatty acids and known as ligands for GPR40 and GPR120. Although they both have antilipogenic properties, DHA is associated with a greater reduction in serum TG levels compared with EPA [21]. In addition, DHA has a lipid control benefit over EPA, as it increases the serum level of high-density lipoprotein (HDL) [22]. Many studies have explored the potentially beneficial effects of GPR40 and GPR120 in various cells and organs. However, possibly due to limited expression of GPR40 and GPR120 in hepatocytes compared with other cell types [23,24], few studies have clearly identified the receptor involved in the antilipogenic effects of omega- 3 fatty acids in the liver. In this study, we investigated the effects of DHA on lipogenic enzyme expression in primary hepatocytes and sought to clarify the related lipid-sensing GPCR exerting its antilipogenesis effect.

GPCRs are usually downregulated to eschew repercussive effects by persistent stimulation with agonists. Nobili et al. reported that patients administered DHA develop increased levels of GPR120 in hepatocytes [25]. This result is consistent with our finding that GPR120 and GPR40 mRNA levels are increased in mouse primary hepatocytes treated with DHA. Although regulatory mechanisms underlying the expression of long-chain fatty-acid-sensing GPCRs are not fully understood, Abaraviciene et al. showed that the GPR40 protein level is increased in response to 100 - and $1000-\mu \mathrm{M}$ palmitate exposures in rat islet [26]. However, GPR40 mRNA expression was enhanced only by $100 \mu \mathrm{M}$ palmitate treatment. Therefore, we expect that both transcriptional and post-translational regulation play a role in the enhanced expression of GPR40 and GPR120 after DHA exposure. Moreover, immunohistochemical analyses using GPR40 and GPR120 antibodies confirmed that both GPR40 and GPR120 were present in mouse primary hepatocytes. Although GPR40 and GPR120 have different molecular structures, they share long chain fatty acids as their endogenous ligands, and the identification of highly specific ligands to discriminate the receptors is difficult [11]. Before CpdA was developed by Merck, TUG-891 was the most selective compound for GPR120. Unfortunately, TUG-891 loses its GPR120 selectivity in murine species [27]. Thus, in this study, CpdA was used to target GPR120 in mouse primary hepatocytes. We found that CpdA did not lower the protein expression of SREBP-1-dependent lipogenic enzymes stimulated by the high glucose with insulin milieu. Moreover, DHA reduced protein levels of preSREBP-1 and FAS in primary GPR120 KO hepatocytes exposed to T090 or high glucose and insulin. From this finding, we suggest that GPR120 is not mainly involved in the antilipogenic effects of DHA in hepatocytes. Contrary to our findings, Kang et al. reported that DHA and TUG-891 decreased LXR-mediated lipogenic protein expression in HepG2 and Hep3B hepatoma cell lines, as well as mouse primary hepatocytes, and further revealed that GPR120 is involved in the antilipogenic effect of DHA [28] .This discrepancy seems to be mainly to differences in the concentration range of DHA in cell-based analyses. In our experimental conditions, protein expression of preSREBP-1 and a series of lipogenic enzymes were suppressed by $300 \mu \mathrm{M}$ DHA treatment. In contrast, others have reported that 10-30 $\mu \mathrm{M}$ DHA efficiently inhibited lipid accumulation by downregulating the SREBP-1 pathway in hepatoma cell lines and 
primary hepatocytes. DHA seems to have a potent binding affinity to GPR120. A DHA concentration $<1 \mu \mathrm{M}$ evoked internalization of GPR120 in HEK293 cells stably expressing GPR120-enhanced green fluorescent protein (EGFP) [24]. Hence, relatively low concentrations of DHA may preferentially stimulate the GPR120 signal, whereas higher concentration act on GPR40. In fact, 10-20 $\mu \mathrm{M}$ DHA induces calcium influx in Chinese Hamster Ovary (CHO) cells expressing GPR40 [29].

Because the $\mathrm{G} \alpha_{\mathrm{q} / 11}$-coupled receptor GPR40 is expressed mainly in pancreatic $\beta$-cells, most of previous studies focused on its potential ability to stimulate insulin secretion. Because GPR40 activation stimulates insulin secretion only in the presence of elevated glucose levels $[9,30,31]$, it has become an attractive potential therapeutic target for glucose homeostasis with little to no hypoglycemic risk. GPR40 is negligibly expressed in the liver [16]. Thus, the functional roles of GPR40 in hepatocytes have received less attention. In this study, we used GPR40 full agonist, AMG-1638, to assess whether GPR40 plays a functional role in hepatocytes. The enhanced lipogenic enzyme levels caused by LXR agonist or high glucose with insulin milieu were diminished by AMG-1638 in primary hepatocytes. Furthermore, GPR40 antagonist GW1100 efficiently abrogated the antilipogenic effects of DHA. These cell-based analyses using specific pharmacological tools suggest that receptor signaling plays an antilipogenic role in primary hepatocytes. Li et al. reported that the GPR40/120 agonist GW9508 improves hepatic steatosis in mice fed a high-cholesterol diet and inhibits LXR ligand-induced expression of lipogenic enzymes in HepG2 cells [12]. They further found that the antilipogenic activity of GW9508 is significantly reversed by GPR40 siRNA, suggesting a pivotal role of GPR40 in the regulation of hepatic lipid accumulation. These data are consistent with our findings.

Taken together, our findings may help to unravel how DHA alleviates fatty acid accumulation in hepatocytes. Furthermore, these findings support the notion of using specific GPCR agonists as an add-on therapy to manage metabolic syndrome and suggest that GPR40 merits further investigation as an adjuvant therapy for NAFLD.

\section{Materials and Methods}

\subsection{Reagent and Antibodies}

Antibody recognizing precursor sterol regulatory element binding protein-1 (SREBP-1) was obtained from Santa Cruz Biotechnology (Dallas, TX, USA). Anti-fatty acid synthase (FAS) and antinuclear form of SREBP-1 antibodies were supplied by BD Biosciences (Franklin Lakes, NJ). Stearoyl-CoA desaturase-1 (SCD1), phospho-AMP-activated protein kinase (p-AMPK), and acetyl-CoA carboxylase (ACC) antibodies were obtained from Cell Signaling Technology (Beverly, MA). Anti-glyceraldehyde 3-phosphate dehydrogenase (GAPDH) antibody and T0901317 (T090) were supplied by Calbiochem (San Diego, CA, USA). Anti- $\beta$ actin antibody, insulin, and glucose were purchased from Sigma-Aldrich (St. Louis, MO). Horseradish peroxidase-conjugated donkey anti-rabbit IgG, and alkaline phosphatase-conjugated donkey anti-mouse IgG were obtained from Jackson Immunoresearch Laboratories (West Grove, PA, USA). Eicosapentaenoic acid (EPA), docosahexaenoic acids (DHA), and compound A (CpdA) were supplied by Cayman Chemical (Ann Arbor, MI, USA). GW1100 and AMG-1638 were kindly donated from LG Chem Ltd. (Seoul, South Korea).

\subsection{Cell Culture}

Human hepatoma cell line HepG2 was obtained from American Type Culture Collection (ATCC, Manassas, VA, USA). HepG2 cells were grown in low-glucose Dulbecco's modified Eagle's medium (DMEM) with 10\% fetal bovine serum (FBS, Gibco, Thermo Fisher Scientific, Waltham, MA, USA) with $50 \mathrm{U} / \mathrm{mL}$ penicillin and $50 \mu \mathrm{g} / \mathrm{mL}$ streptomycin. All cell lines were maintained at $37^{\circ} \mathrm{C}$ in a humidified incubator with $5 \% \mathrm{CO}_{2}$. 


\subsection{Animals}

GPR120 knock-out (KO) C57BL/6 mice were kindly donated from LG Chem Ltd. The mice were housed in a pathogen-free animal facility under a standard $12 \mathrm{~h} \mathrm{light/dark} \mathrm{cycle.} \mathrm{Animal} \mathrm{experiments}$ were conducted under the guidelines of the Institutional Animal Use and Care Committee at Seoul National University (SNU-160512-11-1, 12 May, 2016).

\subsection{Isolation of Primary Hepatocytes}

After anesthetizing 8-weeks-old C57BL/6 mice (DBL, Eumseong, Korea) or GPR120 KO mice with zoletil ${ }^{\circledR}$ and rompun ${ }^{\circledR}, 24 \mathrm{G}$ catheter was cannulated to liver portal vein. After perfusion with Hank's Balanced Salt solution medium (Life Technologies, Grand Island, NY, USA) supplemented with $0.5 \mathrm{mM}$ ethylene glycol tetraacetic acid and $25 \mathrm{mM}$ 4-(2-hydroxyethyl)-1-piperazineethanesulfonic acid (HEPES), liver tissue was digested with low-glucose DMEM containing 1\% penicillin/streptomycin, $15 \mathrm{mM}$ HEPES and $1 \mathrm{mg} / \mathrm{mL}$ collagenase from Clostridium histolyticum (Sigma-Aldrich, St.Louis, MO, USA). After tearing digested liver tissue, the isolated cells were washed three times with high-glucose DMEM supplemented with 10\% FBS, $1 \%$ penicillin/streptomycin, 15 mM HEPES, $10 \mathrm{nM}$ dexamethasone. Other cells except primary hepatocytes were all removed by centrifugation.

4.5. mRNA Isolation and Real-Time Quantitative Polymerase Chain Reaction (qPCR)

After washing with sterile phosphate-buffered saline (PBS), total RNA was isolated using TRIzol reagent (Life Technologies, Grand Island, NY). mRNA was reverse transcribed to cDNA using Maxime RT Premix (iNtRON, Seongnam, South Korea). Amplified cDNA was analyzed by Bio-Rad CFX Manager ${ }^{\mathrm{TM}}$ Software (Bio-Rad, Hercules, CA, USA) using iTaq Universal SYBR Green Supermix (Bio-Rad) and SYBR Select Master Mix (Life Technologies). Primer sequences used in experiments were:

5'-CTGTGCAGGAATGAGTGGAAG-3' (mouse GPR120-forward)

5'-CTGATGGAGGGTACTGGAAATG-3' (mouse GPR120-reverse)

5'-CTGTGCAGGAATGAGTGGAAG-3' (human GPR120-forward)

5'-CTGATGGAGGGTACTGGAAATG-3' (human GPR120-reverse)

5'-TGGCGCGCCAGCCTGG-3' (mouse GPR120 KO-forward)

5'-CCATATGAAAGCCAGCAGTGCC-3' (mouse GPR120 KO-reverse)

5'-CGCCGTCGGCGCCGTG-3' (mouse GPR120 WT-forward)

5'-CCATATGAAAGCCAGCAGTGCC-3' (mouse GPR120 WT-reverse)

5'-TTTCATAAACCCGGACCTAGGA-3' (mouse GPR40-forward)

5'-CCAGTGACCAGTGGGTTGAGT-3' (mouse GPR40-reverse)

5' - GCCCACTTCTTCCCACTCTA-3' (human GPR40-forward)

5' - AGACCCAGGTGACACAGGAC -3' (human GPR40-reverse)

5'-GTAACCCGTTGAACCCCATT-3' (mouse and human 18s rRNA protein-forward)

5'-CCATCCAATCGGTAGTAGCG-3' (mouse and human 18s rRNA protein-reverse)

\subsection{Immunoblot Analysis}

After washing the cultured cells with PBS, cells were lysed in lysis buffer containing $20 \mathrm{mM}$ TrisHCl (pH 7.5), 1\% Triton X-100, $137 \mathrm{mM}$ sodium chloride, 10\% glycerol, $2 \mathrm{mM}$ EDTA, $1 \mathrm{mM}$ sodium orthovanadate, $25 \mathrm{mM} \beta$-glycerophosphate, $2 \mathrm{mM}$ sodium pyrophosphate, $1 \mathrm{mM}$ phenyl methyl sulfonyl fluoride, and $1 \mu \mathrm{g} / \mathrm{mL}$ leupeptin. Cells were then incubated in ice for $1 \mathrm{~h}$. The cell lysates were centrifuged at 10,000 $\mathrm{g}$ for $20 \mathrm{~min}$ to remove debris, and the protein samples were loaded on $8-15 \%$ SDS-PAGE gel and transferred to nitrocellulose membrane (GE healthcare Life Sciences, Chalfont, Buckinghamshire, UK). Membranes were incubated for $1 \mathrm{~h}$ with $5 \%$ skim milk (BD Bioscience, San Jose, CA, USA) and reacted with primary antibodies overnight at $4{ }^{\circ} \mathrm{C}$. The membranes were washed and incubated with a second antibody for $1 \mathrm{~h}$ at room temperature. Protein expression was visualized with LAS3000-mini (Fujifilm, Tokyo, Japan) using enhanced chemiluminescence (ECL) system reagent 
(EMD Millipore, Billerica, MA, USA). Densitometric analysis was performed by using Multiguage software (Fujifilm, Tokyo, Japan) and Image J 1.46r.

\subsection{Hematoxylin and Eosin Staining}

The left lateral lobe of the liver was sliced, and tissue slices were fixed in $10 \%$ buffered-neutral formalin. The liver slices were stained with hematoxylin and eosin (H\&E).

\subsection{Detection of Lipid Droplets (LDs) by Confocal Fluorescence Scanning Microscopy}

For BODIPY ${ }^{\circledR} 493 / 503$ staining (Thermo Fisher Scientific, Waltham, MA, USA), the 488 nm laser was used and signals were collected with a long pass $505 \mathrm{~nm}$ filter. Quantification of LD number and size was performed with MetaMorph, version 7.5 (Molecular Devices, San Jose, CA, USA).

\subsection{Statistical Analysis}

The analyses were performed with IBM ${ }^{\circledR}$ SPSS ${ }^{\circledR}$ Statistics 23 (IBMSPSS Statistics, IBM Corporation). The significance level was set at $p$ value $<0.05$ for all comparisons. Although the size of sample is small, Shapiro-Wilk test showed normality of the data and one-way analysis of variance (ANOVA) was used for multiple comparisons. Tukey's or Dunnett's tests were used as post hoc analysis methods. Statistical analysis for GSE data was performed by using Student's $t$-test and Benjamini-Hochberg test.

Supplementary Materials: Supplementary Materials can be found at http://www.mdpi.com/1422-0067/20/11/ 2625/s1. Figure S1. (A) Functional annotations associated with genes exhibiting lipid metabolism and cholesterol metabolism were altered in the fish-oil-fed mouse. (B) According to GSE32706, genes controlling synthesis of triglyceride including srebf1, $a c a c b, f a s n$, and $s c d 1$ were reduced in the liver from the fish-oil-fed mouse. Data represent means $\pm \mathrm{SD}(\mathrm{n}=3){ }^{*} p<0.05,{ }^{* * *} p<0.05$ compared with the control diet group. Figure S2. (A) Effects of DHA on the expression of lipogenic proteins stimulated by T090. Relative densitometric ratio of FAS and ACC. Data represent means $\pm \operatorname{SD}(n=5),{ }^{\#} p<0.05,{ }^{\# \#} p<0.005$ compared with the T090-treated group. (B) Effects of DHA on the expression of lipogenic proteins stimulated by high glucose and insulin. Relative densitometric ratio of nSREBP-1, FAS, ACC, and SCD-1. Data represent means \pm SD $(n=5)$, ${ }^{* * *} p<0.05$ compared with the control group; ${ }^{\# \#} p<0.005$ compared with the T090-treated group. Figure S3. (A) Relative mRNA expressions of GPR40 and GPR120 levels were determined by real-time qPCR analyses in HepG2 cell line. Data represent means $\pm \operatorname{SD}(n=4),{ }^{* * *} p<0.005$ and ${ }^{\# \# \#} p<0.005$, compared with the GPR40 and GPR120 levels of control group, respectively. (B) Effects of CpdA on the expression of preSREBP-1, and SCD-1 in HepG2 were determined by immunoblottings. (C) Effects of CpdA on the expression of lipogenic proteins stimulated by high glucose and insulin. Relative densitometric ratio of FAS. Data represent means \pm SD $(n=5), * * *<0.05$ compared with the control group. (D) Hematoxylin and eosin (H\&E) staining of liver sections from 8-weeks-old wild-type (WT) and GPR120 mice. Original magnification setting of 200× for H\&E was used. (E) Effects of DHA on the expression of lipogenic proteins in GPR120 KO primary hepatocytes stimulated by T090. Relative densitometric ratio of nSREBP-1 and FAS. Data represent means $\pm \mathrm{SD}(\mathrm{n}=3),{ }^{* * *} p<0.005$ compared with the control group; $\# \#$ \# 0.005 compared with the T090-treated group. (F) Effects of DHA on the expression of lipogenic proteins in GRP120 KO primary hepatocytes stimulated by high glucose and insulin. Relative densitometric ratio of FAS and SCD-1. Data represent means $\pm \mathrm{SD}(n=3),{ }^{* * *} p<0.05$ compared with the control group; ${ }^{\# \#} p<0.01,{ }^{\# \#} p<0.005$ compared with the high glucose and insulin group.

Author Contributions: Conceptualization, K.W.K. and S.O.; Investigation, S.O., H.Y.K., H.S.K. and J.P.; Writing-original draft, S.O., H.Y.K. and K.W.K.; Writing-review \& editing, H.Y.K. and K.W.K.

Acknowledgments: This work was supported by the National Research Foundation of Korea (NRF) grants funded by the Korean Government (2017M3A9C8028794).

Conflicts of Interest: The authors declare no conflict of interest. The funders had no role in the design of the study; in the collection, analyses, or interpretation of data; in the writing of the manuscript, and in the decision to publish the results. 


\section{Abbreviations}

$\begin{array}{ll}\text { ACC } & \text { Acetyl-Coenzyme A carboxylase } \\ \text { ALT } & \text { Alanine transaminase } \\ \text { AMPK } & \text { Adenosine Monophosphate-activated protein kinase } \\ \text { AST } & \text { Aspartate transaminase } \\ \text { CpdA } & \text { Compound A } \\ \text { DHA } & \text { Docosahexaenoic acid } \\ \text { FAS } & \text { Fatty acid synthase } \\ \text { FFA } & \text { Free fatty acid } \\ \text { GPR120 } & \text { G-protein-coupled receptor 120 } \\ \text { GPR40 } & \text { G-protein-coupled receptor 40 } \\ \text { GADPH } & \text { Glyceraldehyde-3-phosphate dehydrogenase } \\ \text { GO } & \text { Gene Ontology } \\ \text { LDs } & \text { Lipid droplets } \\ \text { LXR } & \text { Liver X receptor } \\ \text { NAFLD } & \text { Nonalcoholic fatty liver disease } \\ \text { NASH } & \text { Nonalcoholic steatohepatitis } \\ \text { ND } & \text { Not detected } \\ \text { SCD-1 } & \text { Stearoyl-Coenzyme A desaturase-1 } \\ \text { SREBP-1 } & \text { Sterol regulatory element binding protein-1 } \\ \text { TG } & \text { Triglyceride } \\ \text { T090 } & \text { T0901317 }\end{array}$

\section{References}

1. Perumpail, B.J.; Khan, M.A.; Yoo, E.R.; Cholankeril, G.; Kim, D.; Ahmed, A. Clinical epidemiology and disease burden of nonalcoholic fatty liver disease. World J. Gastroenterol 2017, 23, 8263-8276. [CrossRef] [PubMed]

2. Bedogni, G.; Nobili, V.; Tiribelli, C. Epidemiology of fatty liver: An update. World J. Gastroenterol 2014, 20, 9050-9054. [PubMed]

3. Fan, J.G.; Kim, S.U.; Wong, V.W. New trends on obesity and nafld in asia. J. Hepatol. 2017, 67, 862-873. [CrossRef]

4. Calzadilla Bertot, L.; Adams, L.A. The natural course of non-alcoholic fatty liver disease. Int. J. Mol. Sci. 2016, 17. [CrossRef]

5. Chalasani, N.; Younossi, Z.; Lavine, J.E.; Charlton, M.; Cusi, K.; Rinella, M.; Harrison, S.A.; Brunt, E.M.; Sanyal, A.J. The diagnosis and management of nonalcoholic fatty liver disease: Practice guidance from the american association for the study of liver diseases. Hepatology 2018, 67, 328-357. [CrossRef]

6. Clarke, T.C.; Black, L.I.; Stussman, B.J.; Barnes, P.M.; Nahin, R.L. Trends in the use of complementary health approaches among adults: United states, 2002-2012. Natl. Health Stat. Rep. 2015, 10, 1-16.

7. Backes, J.; Anzalone, D.; Hilleman, D.; Catini, J. The clinical relevance of omega-3 fatty acids in the management of hypertriglyceridemia. Lipids Health Dis. 2016, 15, 118. [CrossRef]

8. Parker, H.M.; Johnson, N.A.; Burdon, C.A.; Cohn, J.S.; O'Connor, H.T.; George, J. Omega-3 supplementation and non-alcoholic fatty liver disease: A systematic review and meta-analysis. J. Hepatol. 2012, 56, 944-951. [CrossRef] [PubMed]

9. Briscoe, C.P.; Tadayyon, M.; Andrews, J.L.; Benson, W.G.; Chambers, J.K.; Eilert, M.M.; Ellis, C.; Elshourbagy, N.A.; Goetz, A.S.; Minnick, D.T. The orphan g protein-coupled receptor gpr40 is activated by medium and long chain fatty acids. J. Biol. Chem. 2003, 278, 11303-11311. [CrossRef]

10. Oh, D.Y.; Talukdar, S.; Bae, E.J.; Imamura, T.; Morinaga, H.; Fan, W.; Li, P.; Lu, W.J.; Watkins, S.M.; Olefsky, J.M. Gpr120 is an omega-3 fatty acid receptor mediating potent anti-inflammatory and insulin-sensitizing effects. Cell 2010, 142, 687-698. [CrossRef]

11. Oh, D.Y.; Walenta, E.; Akiyama, T.E.; Lagakos, W.S.; Lackey, D.; Pessentheiner, A.R.; Sasik, R.; Hah, N.; Chi, T.J.; Cox, J.M.; et al. A gpr120-selective agonist improves insulin resistance and chronic inflammation in obese mice. Nat. Med. 2014, 20, 942-947. [CrossRef] [PubMed] 
12. Li, M.; Meng, X.; Xu, J.; Huang, X.; Li, H.; Li, G.; Wang, S.; Man, Y.; Tang, W.; Li, J. Gpr40 agonist ameliorates liver $x$ receptor-induced lipid accumulation in liver by activating ampk pathway. Sci. Rep. 2016, 6, 25237. [CrossRef] [PubMed]

13. Eberle, D.; Hegarty, B.; Bossard, P.; Ferre, P.; Foufelle, F. Srebp transcription factors: Master regulators of lipid homeostasis. Biochimie 2004, 86, 839-848. [CrossRef] [PubMed]

14. Gluchowski, N.L.; Becuwe, M.; Walther, T.C.; Farese, R.V., Jr. Lipid droplets and liver disease: From basic biology to clinical implications. Nat. Rev. Gastroenterol Hepatol. 2017, 14, 343-355. [CrossRef]

15. Shi, X.; Li, J.; Zou, X.; Greggain, J.; Rødkær, S.V.; Færgeman, N.J.; Liang, B.; Watts, J.L. Regulation of lipid droplet size and phospholipid composition by stearoyl-coa desaturase. J. Lipid Res. 2013, 54, 2504-2514. [CrossRef]

16. Steneberg, P.; Rubins, N.; Bartoov-Shifman, R.; Walker, M.D.; Edlund, H. The ffa receptor gpr40 links hyperinsulinemia, hepatic steatosis, and impaired glucose homeostasis in mouse. Cell Metab. 2005, 1, 245-258. [CrossRef]

17. Huang, G.-M.; Jiang, Q.-H.; Cai, C.; Qu, M.; Shen, W. Scd1 negatively regulates autophagy-induced cell death in human hepatocellular carcinoma through inactivation of the ampk signaling pathway. Cancer Lett. 2015, 358, 180-190. [CrossRef]

18. Paton, C.M.; Ntambi, J.M. Biochemical and physiological function of stearoyl-coa desaturase. Am. J. Physiol. Endocrinol. Metab. 2009, 297, E28-E37. [CrossRef]

19. Wang, Y.; Kurdi-Haidar, B.; Oram, J.F. Lxr-mediated activation of macrophage stearoyl-coa desaturase generates unsaturated fatty acids that destabilize abca1. J. Lipid Res. 2004, 45, 972-980. [CrossRef]

20. Brown, S.P.; Dransfield, P.J.; Vimolratana, M.; Jiao, X.; Zhu, L.; Pattaropong, V.; Sun, Y.; Liu, J.; Luo, J.; Zhang, J.; et al. Discovery of am-1638: A potent and orally bioavailable gpr40/ffa1 full agonist. Acs. Med. Chem. Lett. 2012, 3, 726-730. [CrossRef]

21. Jacobson, T.A.; Glickstein, S.B.; Rowe, J.D.; Soni, P.N. Effects of eicosapentaenoic acid and docosahexaenoic acid on low-density lipoprotein cholesterol and other lipids: A review. J. Clin. Lipidol. 2012, 6, 5-18. [CrossRef]

22. Wei, M.Y.; Jacobson, T.A. Effects of eicosapentaenoic acid versus docosahexaenoic acid on serum lipids: A systematic review and meta-analysis. Curr. Atheroscler. Rep. 2011, 13, 474-483. [CrossRef]

23. Gotoh, C.; Hong, Y.H.; Iga, T.; Hishikawa, D.; Suzuki, Y.; Song, S.H.; Choi, K.C.; Adachi, T.; Hirasawa, A.; Tsujimoto, G.; et al. The regulation of adipogenesis through gpr120. Biochem. Biophys. Res. Commun. 2007, 354, 591-597. [CrossRef]

24. Hirasawa, A.; Tsumaya, K.; Awaji, T.; Katsuma, S.; Adachi, T.; Yamada, M.; Sugimoto, Y.; Miyazaki, S.; Tsujimoto, G. Free fatty acids regulate gut incretin glucagon-like peptide-1 secretion through gpr120. Nat. Med. 2005, 11, 90-94. [CrossRef]

25. Nobili, V.; Carpino, G.; Alisi, A.; De Vito, R.; Franchitto, A.; Alpini, G.; Onori, P.; Gaudio, E. Role of docosahexaenoic acid treatment in improving liver histology in pediatric nonalcoholic fatty liver disease. Plos ONE 2014, 9, e88005. [CrossRef]

26. Abaraviciene, S.M.; Muhammed, S.J.; Amisten, S.; Lundquist, I.; Salehi, A. Gpr40 protein levels are crucial to the regulation of stimulated hormone secretion in pancreatic islets. Lessons from spontaneous obesity-prone and non-obese type 2 diabetes in rats. Mol. Cell. Endocrinol. 2013, 381, 150-159. [CrossRef]

27. Hudson, B.D.; Shimpukade, B.; Mackenzie, A.E.; Butcher, A.J.; Pediani, J.D.; Christiansen, E.; Heathcote, H.; Tobin, A.B.; Ulven, T.; Milligan, G. The pharmacology of tug-891, a potent and selective agonist of the free fatty acid receptor 4 (ffa4/gpr120), demonstrates both potential opportunity and possible challenges to therapeutic agonism. Mol. Pharm. 2013, 84, 710-725. [CrossRef]

28. Kang, S.; Huang, J.; Lee, B.-K.; Jung, Y.-S.; Im, E.; Koh, J.-M.; Im, D.-S. Omega-3 polyunsaturated fatty acids protect human hepatoma cells from developing steatosis through FFA4 (GPR120). Biochim. Biophys. Acta Mol. Cell Biol. Lipids. 2018, 1863, 105-116. [CrossRef]

29. Itoh, Y.; Kawamata, Y.; Harada, M.; Kobayashi, M.; Fujii, R.; Fukusumi, S.; Ogi, K.; Hosoya, M.; Tanaka, Y.; Uejima, H. Free fatty acids regulate insulin secretion from pancreatic $\beta$ cells through gpr40. Nature 2003, 422, 173. [CrossRef] 
30. Feng, X.T.; Leng, J.; Xie, Z.; Li, S.L.; Zhao, W.; Tang, Q.L. Gpr40: A therapeutic target for mediating insulin secretion (review). Int. J. Mol. Med. 2012, 30, 1261-1266. [CrossRef]

31. Syed, I.; Lee, J.; Moraes-Vieira, P.M.; Donaldson, C.J.; Sontheimer, A.; Aryal, P.; Wellenstein, K.; Kolar, M.J.; Nelson, A.T.; Siegel, D.; et al. Palmitic acid hydroxystearic acids activate gpr40, which is involved in their beneficial effects on glucose homeostasis. Cell Metab. 2018, 27, 419-427.e414. [CrossRef] [PubMed]

(C) 2019 by the authors. Licensee MDPI, Basel, Switzerland. This article is an open access article distributed under the terms and conditions of the Creative Commons Attribution (CC BY) license (http://creativecommons.org/licenses/by/4.0/). 